Revista de
Economía
Contemporâned

\title{
DESENVOLVIMENTOECONÔMICO E POLÍTICA INDUSTRIAL E TECNOLÓGICA: A VISÃO DO PROFESSOR FABIO ERBER
}

\begin{abstract}
Dulce Monteiro Filha ${ }^{\text {a }}$

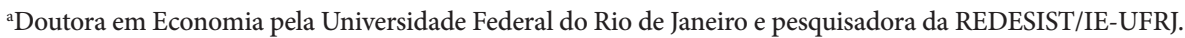

Artigo recebido em 22/03/2017 aceito para publicação em 22/03/2017.

RESUMO: O texto ilustra o caminho teórico seguido pelo Professor Fabio Erber na construção de sua formação acadêmica, mostrando as conclusões da tese que escreveu para obter o grau de Doutor em Economia na Universidade de Sussex , assim como, aquela que lhe propiciou o título de professor titular do Instituto de Economia da Universidade Federal do Rio de Janeiro. Este artigo apresenta, também, os estudos sobre Convenções que estava realizando no Pós-Doutorado na Université de Paris XIII. Erber era um profissional respeitado por ex-colegas, alunos e amigos brasileiros e estrangeiros (latino-americanos, franceses, ingleses, etc.), tendo contribuído para o pensamento latino-americano no que diz respeito aos temas que estudou.
\end{abstract}

PALAVRAS-CHAVE: biografia; Fabio Erber; desenvolvimento; política industrial; política tecnológica; convenção do desenvolvimento.

Correspondência para: Dulce Monteiro Filha

Contato: dulcefilha@globo.com 


\title{
ECONOMIC DEVELOPMENT AND INDUSTRIAL AND TECHNOLOGICAL POLICY: THE VISION OF PROFESSOR FABIO ERBER
}

\begin{abstract}
The present paper illustrates the academic line of Professor Fabio Erber, focusing on the conclusions of his doctoral dissertation from the University of Sussex in Economics, "Technological development and State intervention: a study of the Brazilian capital goods industry", and another important thesis he wrote to became a tenured professor of the Institute of Economics of the Federal University of Rio de Janeiro with "A transformation of regulatory framework: development, technology and state intervention in industrialized nations and in Brazil". Also included in this paper are Dr. Erber's studies on Conventions during his post-doctorate programme at Université de Paris XIII. With vast academic experience, Dr. Erber wrote more than 120 papers besides holding significant government positions. Colleagues, students and friends both Brazilian and from abroad held Dr. Erber in high regard for his Latin America perspective on the topics he pursued.
\end{abstract}

KEYWORDS: biography; Fabio Erber; development; industrial policy; technological policy; development convention 


\section{INTRODUÇÃO}

Com ampla formação cultural, o Professor Fabio Erber ao longo de sua vida profissional caracterizou-se por ser um pensador, tendo mesclado suas atividades acadêmicas com a de operador de políticas públicas. Na juventude dedicou-se também ao teatro. Mas, certamente, seus alunos se lembram dele por sua seriedade e humor peculiar, mas também pela cordialidade e educação refinada.

Era um profissional respeitado por ex-colegas, alunos e amigos brasileiros e estrangeiros (latino-americanos, franceses, ingleses, etc.), alguns dos quais publicaram em sua homenagem capítulos no livro "Estratégia de Desenvolvimento, Política Industrial e Inovação: ensaios em memória de Fabio Erber", editado pelo BNDES. Nesse livro percebe-se a importância de Fabio para o pensamento latino-americano (ver AROCENA e STUZ, 2014), no que se refere aos temas que estudou. Dada a dificuldade de sintetizar toda a sua contribuição acadêmica, pois publicou mais de 120 obras sobre assuntos diversos (como política antitruste, setor petroquímico, etc.), o texto que se segue procura mostrar apenas os que fizeram parte de sua formação acadêmica (teses de doutoramento e do concurso para professor titular do Instituto de Economia da Universidade Federal do Rio de Janeiro, e artigo publicado em Paris quando do pós-doutoramento). Estes trabalhos estão, certamente, no centro da estruturação de seu pensamento, mas não mostram toda a riqueza de seu trabalho.

Graduado em 1965 em Economia pela Universidade Federal do Rio de Janeiro, fez mestrado em Economia do Desenvolvimento pela University of East Anglia (1971), doutorado em Economia pela University of Sussex (1978) e pós-doutorado na Université de Paris XIII (2007).

Sua vida profissional como economista deu-se entre o período conhecido como o do "Milagre Econômico" e o fim do segundo governo Lula (ver PRADO,2014).

Fabio Erber foi professor titular do Instituto de Economia da Universidade Federal do Rio de Janeiro (IE-UFRJ), onde ministrou aulas nas áreas de Política Econômica Brasileira, Economia Brasileira, Economia Interindustriais, Política Científica e Tecnológica, Política Industrial, Política Industrial no Brasil, Teoria do Desenvolvimento Econômico e Tópicos Especiais em Política Industrial e Tecnológica. Pode-se dizer que lecionou e refletiu, principalmente, desde 1982 até a sua morte, sobretemas das áreas de teoria do desenvolvimento, política industrial e tecnológica e suas relações com a política macro (EARP, 2014).

No início de sua vida entrou para o quadro técnico do BNDES, onde trabalhou com José Pelúcio Ferreira, que, em julho de 1967, foi incumbido da criação e implantação da FINEP. Seu objetivo era financiara elaboração de estudos para projetos e programas de desenvolvimento econômico, observando prioritariamente o aperfeiçoa- 
mento da tecnologia nacional ${ }^{1}$. Fabio, funcionário do BNDES, foi cedido à FINEP e fez parte de sua direção e administração, tendo sido o criador do Grupo de Pesquisas da nova agência.

\section{POLÍTICA DE IMPLANTAÇÃO DE UMA INDÚSTRIA NASCENTE NO BRASIL: BENS DE CAPITAL (INCLUI ELETRÔNICA)}

Na FINEP, dedicou-se ao estudo do setor de bens de capital e, em 1978, foi para a Inglaterra, onde obteve o grau de Doutor em Economia pela University of Sussex com a tese "Technological development and Stateintervention: a study of the Brazilian capital goods industry". Esta tese discute a obtenção da capacidade de design local na indústria de bens de capital em países menos desenvolvidos. Mostra, também, a relevância do "conteúdo local" para a competitividade da indústria brasileira. Este é um problema da economia brasileira até os dias atuais, notadamente com relação à implantação de novas indústrias de ponta (como, por exemplo, a de semicondutores), ainda não devidamente instaladas no país.

Analisou esta questão à luz da possibilidade de usar o licenciamento de tecnologia de empresas de países mais avançados e de viabilizar o desenvolvimento dessa capacidade com políticas de Estado (no caso brasileiro). Neste trabalho destacou a importância de: (a) haver condições técnicas dentro da indústria para ser capaz de absorver conhecimento técnico e tecnológico; (b) compreender que a dificuldade em implementar uma política para aumentar a capacidade de design local decorria do padrão de desenvolvimento seguido no Brasil (desde a metade dos anos 1950) e da composição de interesses por trás dele; (c) entender que este padrão de desenvolvimento requeria um tipo de requisito demandado pelos sponsors (patrocinadores, acionistas) e pelo mercado: a alternativa de licenciamento de tecnologias (e não soluções locais específicas); (d) ter faltado uma estratégia de longo prazo, pois, no caso brasileiro, o Estado seguiu uma política de curto prazo e fragmentada; (e) uma política nacionalista, que poderia ter provido a estrutura necessária para uma prospectiva de longo prazo unindo o Estado e os empresários, mas que acabou apresentando um declínio em face da importante presença de empresas estrangeiras nos setores implantados no Brasil.

Em artigo que havia publicado anteriormente em coautoria com José Tavares de Araújo Jr. (1973) já discutia o setor de bens de capital, ressaltando que: (i) a criação de

\footnotetext{
1 Fabio Erber era um especialista também em política tecnológica e, em 2010, publicou um texto bastante interessante sobre o tema (ver ERBER, 2010b).
} 
excedentes neste setor são apropriados pelo resto do sistema econômico, (ii) é um veículo de incorporação e difusão de progresso tecnológico, (iii) evita a limitação da taxa de crescimento da economia; e (iv) permite a autonomia política (AROCENA e SUTZ, 2014, p. 24).

Entre 1986 e 1988 participou da criação do Ministério de Ciência e Tecnologia (MCT), com o ministro Renato Archer e Luciano Coutinho, como vice-ministro. Fabio Erber foi secretário executivo adjunto, e seu companheiro de Sussex/Inglaterra - o professor José Cassiolato foi secretário de planejamento. A amiga - professora Helena Lastres - chefiava o núcleo de novos materiais.

Em 1988, o grupo se reencontrou no Instituto de Economia da UFRJ. A tese de Erber, apresentada neste ano para a obtenção do título de professor titular do IE/UFRJ, foi um estudo da macroeconomia baseado na escola francesa: "A transformação dos regimes de regulação: desenvolvimento, tecnologia e intervenção do Estado nos países industrializados e no Brasil".

De 1992 a 1994 foi, pela primeira vez, Diretor do BNDES na gestão do Professor do IE-UFRJ Antônio Barros de Castro. Nesse período, fui orientanda de Erber no doutorado e, mais tarde, sua assessora, quando, pela segunda vez, voltou a ser Diretor do BNDES. Foi interessante observar no contato com Fabio Erber que, usualmente, quando começava um raciocínio, buscava conceitos (no sentido que identifico como o usado por Deleuze) nascidos da observação do mundo prático e de um vasto cabedal de leituras, procurando muitas vezes estruturar definições, que se caracterizavam pela lucidez.

\section{PADRÃO DE DESENVOLVIMENTO E PADRÃO DE INDUSTRIALIZAÇÃO}

Esta maneira de pensar e adquirir conhecimento repousava na sua concepção de mundo, que, por ser um homem culto, era bastante ampla. Preocupado com o delineamento de políticas para promover o desenvolvimento do país verificou, assim, a importância da interdependência entre políticas. Desta forma, junto com os temas que passou mais frequentemente a analisar - desenvolvimento e industrialização - manteve a preocupação com a coordenação das políticas econômicas macro-meso-micro.

\subsection{PADRÃO DE DESENVOLVIMENTO}

O marco analítico, que estabeleceu, iniciou com a noção de padrão de desenvolvimento, analisando as relações no campo da Economia, definindo-o como: 
"padrão de desenvolvimento"-conjunto de relações entre os agentes econômicos e sociais que garante a manutenção dos processos de acumulação de capital e de preservação do poder político;

"relações econômicas"- normas de acumulação, de produção, de consumo, de financiamento do setor privado e público, de inovação e difusão do processo técnico, de intervenção do Estado, de inserção internacional.

Em artigo publicado em 1992, Erber parte da premissa que as relações econômicas estruturais de um padrão de desenvolvimento movem-se, em nível nacional, dentro de certos limites estabelecidos na esfera internacional, articulando a história nacional com a do sistema. Dentro destes limites, as relações são seletivas, definindo um elenco de problemas a serem tratados e as formas de solucioná-los, assumindo um caráter cumulativo, que na tradição kuhniana, chamam-se "normas" ou "paradigmas".

Chama a atenção o fato de que a crise de uma das normas pode ser compensada pela ação de outras normas ou a crise pode ser do padrão de desenvolvimento como um todo (várias normas entrando em crise).

Nos tempos atuais, de mudanças profundas na sociedade brasileira, e até mesmo no mundo, Fabio diria que a crise parece ser do padrão de desenvolvimento, embora este tema necessite de mais estudos.

\subsection{PADRÃO DE INDUSTRIALIZAÇÃO}

No que se refere ao padrão de industrialização, Fabio Erber reconhece a diferença estrutural que existe na indústria dos países (e nas suas histórias). Entretanto, do ponto de vista do padrão de transformação da industrialização capitalista contemporânea reconheceu que o conceito de "setor industrial" dependendo do foco da análise deveria ser substituído pelo de "complexo industrial", que deveria ser tratados de dois ângulos:

- Pelas relações de compra e venda interindustriais (forma horizontal de "espinha de peixe");

- Pela base técnica (forma horizontal de "leque").

Especificou que a evidência empírica, quanto aos fluxos internacionais de inovações, mostrava que os setores industriais podem ser agrupados em três grupos: setores motores da inovação, setores receptores e setores intermediários.

Para que um sistema econômico seja dinâmico e competitivo em termos internacionais é necessário que conte, internalizados no país, com os complexos motores da inovação. Além disso, a indústria necessita contar com sistemas de apoio adequados. 
A coordenação de instituições tecnológicas, científicas e educacionais, dado as características dos setores motores, é fundamental. A operação conjunta do setor industrial e destes "sistemas de apoio" tem efeitos de aprendizado e sinergia, configurando uma capacidade "sistêmica" de transformação endógena.

\section{POLÍTICA INDUSTRIAL PARA UM NOVO PADRÃO DE DESENVOLVIMENTO}

A atualidade das ideias de Fabio Erber parece evidente, pois, seguindo sua linha de pensamento, é preciso introduzir inovações na indústria, desenvolvendo inclusive políticas mais inclusivas, e inserindo complexos "portadores de futuro", para torná-la mais competitiva. Há a necessidade da adoção de políticas reestruturantes, que possibilitem fugir da competição apenas por preços (do efeito China), uma vez que a indústria não tem conseguido se recuperar desde 2014.

Como Fabio explicou, a interdependência entre políticas requer marco analítico apropriado, para o qual a noção de padrão de desenvolvimento parece um ponto de partida.

Um padrão de desenvolvimento industrializante é aquele em que as várias "normas" que o caracterizam convergem para tornar prioritários a constituição e o desenvolvimento da indústria. Há a convergência de políticas industriais explícitas e implícitas. Entendia como políticas explícitas as que são definidas pela ação do Estado, que visam, diretamente, alterar o comportamento das empresas industriais, direcionando de forma específica à mudança pretendida. Por políticas implícitas, as que procuram alcançar determinados objetivos que são definidos, em parte, à luz da teoria sobre o processo de desenvolvimento.

Assim, em sua concepção ${ }^{2}$, a política industrial (MONTEIRO FILHA e ANDRADE, 2014) faz parte de um sistema, de forma que sua eficácia depende da convergência de políticas implícitas com as demais políticas, principalmente com a macroeconômica, assim como com os objetivos do desenvolvimento que o Estado pretende alcançar.

Fabio chamava a atenção para o fato de que políticas macroeconômicas têm rebatimentos setoriais distintos. E, igualmente, a heterogeneidade das empresas, quanto a tamanho e origem do capital, introduz diferenças importantes na lógica de transformação do conjunto - reforçando a necessidade de políticas industriais diferenciadas.

\footnotetext{
2 Mesma concepção usada em Coutinho e Ferraz (1993).
} 
Como Diretor do BNDES pela primeira vez, de 1992 a 1994, implantou as gerências de estudos setoriais para analisar estas distinções.

Enfatizava que, para um país retardatário, o timing é importante para que possa ocorrer o catching-up com os países desenvolvidos e sustentava que a política industrial acelera esse processo (ERBER, 2002). A ausência de política é uma política de manutenção do status quo, isto é, "mais do mesmo", e não uma situação de não política. Políticas de desenvolvimento geram desequilíbrios para promover o emparelhamento com os países mais adiantados, porque mudanças estruturais ocorrem neste contexto. A política industrial é, assim, um instrumento poderoso na promoção do desenvolvimento (ERBER, 2002).

Fabio Erber, voltando a ser Diretor do BNDES de 2003 a 2004, participou ativamente da volta da Política Industrial (ERBER, 2002), na elaboração da Política Industrial, Tecnológica e de Comércio Exterior (PITCE) em 2004. Entretanto sua preocupação não foi só com a elaboração de política industrial, mas como manter os mesmos objetivos ao longo do tempo. Usualmente os instrumentos de políticas morrem com as mudanças no campo político. Neste sentido, passou a estudar "Convenções” para verificar como as políticas se estabeleciam e como decisões poderiam perdurar.

\section{POLÍTICA: NECESSIDADE DO ESTABELECIMENTO DE CONVENÇÕES}

No artigo que apresentou em debate na Université de Paris XIII em 2008, explicitou que o arcabouço teórico dos seus estudos sobreo tema das convenções partiu da observação de Keynes sobre o "homem prático" sendo guiado por ideias de economistas mortos e quis verificar como isto acontece. Mostra que Schumpeter apresentou boas respostas para esta pergunta. No início (SCHUMPETER, 1954) trabalhou com a evolução destas ideias, explicitando o "intellectualisterror" e argumentou que um dos dois caminhos que molda a "scienceofeconomics" era o "interest in practical problems of the day" (ERBER, 2008 e 2012). Posteriormente, na History of Economic Analysis, Schumpeter fez a distinção entre "pure economics" (teoria econômica como uma caixa de ferramentas) de "Systems of Political Economy" que suportam o estabelecimento de políticas econômicas unificadas por princípios normativos, tais como o liberalismo e o socialismo.

Ainda hoje, numa época de profundas mudanças no mundo, em que a incerteza, a instabilidade e a insegurança permeiam as humanidades e as ciências, os ensinamentos de Fabio Erber sobre convenções são importantes.

Participando de um mundo em guerra ideológica/religiosa, Fabio sempre rejeitou o radicalismo de um mundo dividido entre bons e maus, procurando sempre a possibilidade do estabelecimento de convenções. 
Os conceitos, trazidos para o entendimento do mundo real, eram expostos de forma a estruturar formas de ação política, que eram confrontados com interesses comuns já manifestados na sociedade ou em construção por grupos de interesses, que se propunham traçar convenções.

As convenções tornam-se vitais ao estabelecimento de políticas que, quando embasadas em articulações mais amplas, têm uma possibilidade maior de serem implantadas. Cabe, contudo, chamar a atenção para o fato de que elas são localizadas no tempo e no espaço e, só com grande dificuldade, passam a incorporar a cultura. Mesmo assim, uma vez criados arcabouços institucionais e administrativos, é difícil desestruturar o que foi estabelecido na convenção anterior, o que só ocorre parcialmente, numa maior ou menor proporção. Essa resistência decorre da incorporação de ideias e valores que foram introjetados nas pessoas, que pertencem a diversos grupos sociais.

Ao estudar as convenções sociais, Fabio Erber definiu este conceito como a identidade compartilhada por uma "geração sociológica" em termos de visão de mundo, seus objetivos, caminhos a serem seguidos e meios aceitáveis para alcançar estes objetivos. É um sistema cognitivo que serve de guia para as práticas sociais e atua como um elemento fundamental, para a redução de incerteza e para a coordenação dos agentes econômicos e políticos (ORLÉAN, 1989). Estas ideias, que formavam a estrutura de pensamento de Fabio Erber, foram expressas quando escreveu, em 1988, sua tese de docência para a UFRJ, intitulada "A transformação dos regimes de regulação: desenvolvimento tecnológico e intervenção do Estado nos países industrializados e no Brasil", na qual utilizou a metodologia dos trabalhos de economistas regulacionistas parisienses, notadamente AGLIETTA (1976) e CORIAT (1982).

Uma convenção é um dispositivo cognitivo que faz prevalecer as atitudes "confirmacionistas" (como explicitado por Keynes na Teoria Geral) conduzindo a uma rotinização de cálculos e de decisões, embora não se reduza a apenas um esquema cognitivo. Orienta a prática que norteia a ação dos agentes que a subscrevem. Sua análise requer o estudo das práticas sociais que dela decorrem e, idealmente, do processo de interação entre o esquema cognitivo e a sua práxis.

O interesse de Fabio Erber era analisar a convenção do desenvolvimento, de forma que se propôs realizar no Pós-Doutorado o trabalho "Development Conventions: The Political Economy of Development Theory”. Ao estudar a transformação da sociedade e da economia brasileira verificou que, antes esta seguia uma convenção do desenvolvi$\underline{\text { mento }}$ e que depois passou a ser predominante uma convenção neoliberal. Erber identificou o fracasso do Plano Cruzado como o marco divisório da representação social dessa mudança no Brasil (ERBER, 2007), e fez um contraponto à convenção de desenvolvimento com a liberal. 
Na convenção do desenvolvimento, o núcleo central dos esforços de investimento foram os setores industriais, já que a matriz industrial precisava ser completada. Os planos brasileiros de estabilização do período desenvolvimentista não tiveram a preocupação de mudar o modelo, contudo as reformas financeiras de 1964/65 tentaram implantar um modelo financeiro baseado na especialização de instituições financeiras que atenderiam a segmentos específicos do mercado de crédito e de capitais, diferenciando os instrumentos de captação e de aplicação de recursos. Nos anos 1980, os planos de estabilização se preocuparam com o impacto no emprego das medidas adotadas ${ }^{3}$.

Na convenção liberal que no Brasil se tornou hegemônica nos anos 1990, o núcleo central é constituído, segundo Erber, por uma visão dos seguintes problemas (ERBER, 2007, p. 41): a) ineficácia de políticas ativas do Estado; b) “apropriação" do Estado por interesses particulares - seja por coalizões restritas, seja pela própria burocracia; c) necessidade de desenvolvimento de instituições adequadas que, na fase atual do capitalismo, estimulassem a inovação e reduzissem os custos de transação. Embora indispensáveis, as instituições estatais deveriam ser tão market friendly quanto possível, de preferência "simulando a atuação do mercado, de forma a privilegiar a alocação eficiente de recursos e inovação".

A convenção neoliberal tinha uma visão diferente com relação à dinâmica da sociedade pela qual o desenvolvimento, adequadamente conduzido, levava necessariamente a uma sociedade "pós-histórica", regida pelo mercado e com um sistema político de democracia representativa (ERBER, 2007, p. 41).

Assim, o modelo de estabilização, implantado nos anos 1990, levou a uma mudança de convenções e rotinas, uma modificação no arcabouço institucional no país, que aumentou a influência política de uns grupos econômicos em detrimento de outros. Suzigan (1998) argumenta que a instabilidade econômica com a inflação acelerada e a inoperância do Estado em termos de política industrial e tecnológica levou a cristalização de uma conformação estrutural caracterizada por acentuadas heterogeneidades tecnológicas e estruturais e por fraca capacidade de inovação, que passaram a serem óbices à retomada do crescimento. Os problemas enfrentados pela estrutura produtiva eram visto por todos como um esgotamento do modelo de desenvolvimento, identificado pela queda dos índices de produtividade (CHAGAS, 2006).

No desenvolvimento de um modelo de estabilização, os interesses financeiros se tornaram prioritários e vários dos grandes grupos nacionais ampliaram seus coeficientes de abertura. Houve sem dúvida um avanço na área de serviços (principalmente bancários e telecomunicações), mas também se desenvolveram grandes empresas in-

\footnotetext{
3 Levaram em consideração o trade-off entre inflação e desemprego (curva de Phillips).
} 
dustriais, que modificaram profundamente suas decisões estratégicas no que se referia ao modo de valorização de seu capital, se transformando claramente em grupos financeiros (SERFATI, 1998), movimento que se iniciou em decorrência da crise de 1982.

A coordenação central da nova estrutura neoliberal ${ }^{4}$ usou assim, como instrumentos, um modelo de estabilização e um regime monetário de metas de inflação. O modelo de estabilização rejeitou a interdependência entre políticas econômicas no alcance de metas planejadas ${ }^{5}$, defendendo também que uma política monetária subserviente à fiscal pode prejudicar o controle da inflação, assim como, salientou que a predominância da política monetária sobre a fiscal pode não ser suficiente para contornar o problema. Uma condição a ser satisfeita era que a taxa de juros não poderia fixada acima do crescimento do PIB, pois, dessa forma, a economia podia entrar em uma rota explosiva da razão dívida/PIB no caso de persistência de déficits fiscais.

Foi traduzido, num conjunto de recomendações, um decálogo, que ficou muito conhecido de todos: o Consenso de Washington, originariamente destinado a países da América Latina, mas rapidamente ampliado para países em desenvolvimento.

Contrapondo as duas convenções, Erber identificou quatro aspectos fundamentais que as definem:

- O desenvolvimentismo partia da sociedade para chegar ao agente individual. Na convenção neoliberal, o percurso é oposto.

- A velha convenção via o desenvolvimentismo como a transformação da estrutura produtiva, no sentido que a estrutura institucional que ia se adequando a esta transformação, ao passo que a recomendação básica da convenção neoliberal é get the institutions right, acerto que levaria a uma estrutura produtiva apropriada a uma alocação eficiente de recursos.

- O Estado é para o desenvolvimentismo o motor do desenvolvimento, seja por causa das falhas de mercado, seja por que representa o interesse da coletividade. Para os neoliberais, as falhas do Estado são mais daninhas que as falhas de mercado, e o Estado tende a ser apropriado e deve ter o seu poder discricionário limitado ao máximo. Os mercados, ao contrário, devem ser estimulados e, quanto mais completos, maior será a probabilidade de desenvolvimento.

- Os desenvolvimentistas insistiam que o subdesenvolvimento é um processo histórico específico e que a história dos países periféricos não é uma repetição defasada do percurso dos países mais avançados. Os neoliberais recuperaram o

4 Erber chamou esta coordenação de programa de estudo novo-clássico

5 Pesquisadores do FMI, LAURENS e LA PIEDRA (1998) verificaram que a falta de coordenação entre as autoridades monetária e fiscal pode levar a uma baixa "performance" econômica (ver MENDONÇA, 2003). 
etapismo, numa versão ainda mais simplificada que as prevalecentes nos anos sessenta, como a de ROSTOW (1964) .

Com sua morte prematura o estudo sobre "Development Conventions: The Political Economy of Development Theory" do Pós-Doutorado não foi concluído. Neste texto, utilizamos alguns artigos que escreveu sobre o tema, inclusive as questões e debates publicados na "La Lettredu CEPN (le quatrième numéro)", já citado, que analisa o papel e a importância das convenções de desenvolvimento na dinâmica de crescimento e na definição das políticas econômicas dos países em desenvolvimento.

\section{CONCLUSÃO}

A evolução do pensamento de Fabio Erber sobre economia decorreu dos caminhos percorridos em sua vida profissional. Após entrar no BNDES (1964-1994), tornou-se mestre em Desenvolvimento Econômico (1971) e foi, neste mesmo ano, para a FINEP. Na época do Segundo Plano Nacional do Desenvolvimento (II PND) se envolveu com a proposta da implantação do setor de bens de capital, notadamente com a Política de Informática. Nesta época, o estudo desse setor abrangia conhecimentos de mecânica, elétrica e eletrônica. Foi então para Sussex/Grã-Bretanha e elaborou a sua tese de doutoramento (1978) sobre este tema.

Ao voltar em 1979 passou a ser professor do Instituto de Economia Industrial da UFRJ (atual IE-UFRJ) e fez concurso para professor titular, em 1982, com uma tese sobre desenvolvimento, tecnologia e intervenção do Estado nos países industrializados sob a ótica da teoria francesa de regimes de regulação. Dedicou-se como professor, a partir de então, aos estudos sobre o complexo eletrônico e sobre desenvolvimento industrial e tecnológico.

Em 1985, sob a gestão de Renato Archer, participou da criação do Ministério de Ciência e Tecnologia (atual MCTI), sob a chefia do Professor Luciano Coutinho.

Ao vivenciar o desmonte dos conceitos do desenvolvimentismo, como política de governo após o Plano Collor (1990), observou que essa mudança profunda não se deu apenas no nível de políticas, mas das convenções que sustentavam o estabelecimento das mesmas.

6 Rostow defendeu a tese de que as sociedades atravessam cinco etapas de evolução econômica: 1) etapa da economia tradicional; 2) as pré-condições para a arrancada desenvolvimentista (take-off); 3) participação no processo de desenvolvimento, quando o crescimento se torna um quadro normal do quadro econômico; 4) idade madura, quando uma economia está em condições de utilizar todas as potencialidades da tecnologia disponível; 5) etapa de desenvolvimento pleno, que coincide com um elevado consumo de massa. 
Como Diretor do BNDES de 1992 a 1994 implantou as gerências de estudos setoriais preocupado com a adaptação da instituição à nova convenção, pois achou que era necessário estudar os impactos setoriais das políticas macroeconômicas da convenção neoliberal.

Após este período, dedicou-se à atividade acadêmica de maneira mais intensa até que em 2003 voltou a ser Diretor do BNDES pela segunda vez e foi um dos principais artífices da PITCE (Política Industrial e Tecnológica e de Comércio Exterior), que marcou a volta de conceitos da convenção desenvolvimentista, mas adaptados a uma economia aberta num mundo instável, inseguro e incerto.

Fabio Erber não chegou a concluir uma teoria da convenção desenvolvimentista, como desejava.

\section{REFERÊNCIAS}

AMSDEN, A. A Ascensão do "Resto": os desafios ao Ocidente de economias com industrialização tardia. São Paulo: Editora UNESP, 2009.

AROCENA, R.; SUTZ, J. "El aporte de Fabio Erberal pensamento sobre el desarrollo: mirada sumaria desde Uruguay”. In: MONTEIRO FILHA, D. C.; PRADO, L. C. D.; LASTRES, H. M. M. Estratégia de desenvolvimento, política industrial e inovação: ensaios em memória de Fabio Erber. Rio de Janeiro: BNDES, 2014, p.139.

BIELSCHOWSKY, R. Pensamento econômico brasileiro: o ciclo ideológico do desenvolvimentismo. Rio de Janeiro: IPEA, 1988.

CARVALHO, L. B.; KUPFER, D. Diversificação ou especialização: uma análise do processo de mudança estrutural da indústria brasileira. Revista de Economia Política, v. 31, p. 618-637, 2011.

CHAGAS, A. M. C. T. A economia política comercial brasileira nos anos 90. Tese (Doutorado em Economia) - Instituto de Economia, Universidade Federal do Rio de Janeiro, Rio de Janeiro, 2006.

EARP, F. S. "Fabio Erber e a pedagogia a quatro mãos". In: MONTEIRO FILHA, D. C.; PRADO, L. C. D.; LASTRES, H. M. M. (Orgs.). Estratégia de desenvolvimento, política industrial e inovação: ensaios em memória de Fabio Erber. Rio de Janeiro: BNDES, 2014.

ERBER, F. S. The evolution of development conventions. Revista de Economia Contemporânea, v. 16, n. 1, jan./abr., 2012.

ERBER, F. S. As convenções de desenvolvimento no governo Lula: um ensaio de economia política. Revista de Economia Política, v. 31, n. 1, jan./mar., 2011.

ERBER, F. Convenções de desenvolvimento no Brasil contemporâneo: um ensaio de economia política. Textos para Discussão, CEPAL-IPEA, n. 13, 2010a.

ERBER, F. S. Inovação tecnológica na indústria brasileira no passado recente: uma resenha da literatura econômica. Textos para Discussão, CEPAL-IPEA, n. 17, $2010 \mathrm{~b}$. 
ERBER, F. Convenções de desenvolvimento no Brasil contemporâneo. Insight Inteligência, ano XI, n. 44, 2009.

ERBER, F. S. Eficiência coletiva em arranjos produtivos locais industriais: comentando o conceito. Nova Economia, v. 18, n. 1, p. 11-31, 2008a.

ERBER, F. S. The Evolution of Development Conventions. Le Lettre du CEPN, n. 4, nov. $2008 \mathrm{~b}$. Disponível em: <https://cepn.univ-paris13.fr/lettres-du-cepn/>. Acesso em: 10 jun. 2017.

ERBER, F. S. “The evolution of development conventions”. In: Congresso da Sociedade Internacional J. A. Schumpeter, 12, Rio de Janeiro, IE/UFRJ, 2-5 jul. 2008c.

ERBER, F. S. Development projects and growth under finance domination - the case of Brazil during the Lula years (2003-2007). Revue Tiers Monde, n. 194, p. 597-629, 2008d.

ERBER, F. S. "As convenções de desenvolvimento no Brasil: um ensaio de economia política”. In: Fórum de Economia da FGV-SP, 5, São Paulo, set. 2008e.

ERBER, F. S. “Celso Furtado e as Convenções do Desenvolvimento”. In: SABÓIA, J. M.; CARVALHO, F. J. C. (Orgs). Celso Furtado e o Século XXI. Barueri: Manole / Rio de Janeiro: Instituto de Economia da UFRJ, 2007 p. 52-57.

ERBER, F. S. Innovation and the development convention in Brazil. Revista Brasileira de Inovação, v. 3, n. 1, p. 35-54, 2004. Disponível em: <http://www.ige.unicamp.br/ojs/index.php/ rbi/issue/view/27>. Acesso em: 6 jun. 2017.

ERBER, F. S. Desenvolvimento econômico: o recorte setorial. Rio de Janeiro: BNDES, 2002a.

ERBER, F. “O retorno da política industrial”. In: LEITE, A. D.; REIS VELLOSO, J. P. (Orgs.). O novo governo e os desafios do desenvolvimento. Rio de Janeiro: José Olympio, 2002b.

ERBER,F. S. The Brazilian development in the nineties. Myths, circles and structures. Nova Economia, v. 12, n. 1, jan./jun., 2002c.

ERBER, F. S. “Desenvolvimento econômico: o recorte setorial”. In: BNDES. BNDES 50 Anos Histórias Setoriais. São Paulo: DBA e Rio de Janeiro: BNDES, 2002d, p. 13-14.

ERBER, F. S. Perspectivas da America Latina em Ciência e Tecnologia. Parcerías Estratégicas, n. 8, p. 181-200, 2000.

ERBER, F. S. The political economy of technological development-the case of the Brazilian informatics policy. UNU/INTECH, apr. 1993. Mimeo.

ERBER, F. S.Desenvolvimento Industrial e Tecnológico da década de 90: Uma nova política para um novo padrão de desenvolvimento. Ensaios FEE, v. 13, n. 1, p. 9-42, 1992.

ERBER, F. S. A transformação dos regimes de regulação: desenvolvimento, tecnologia e intervenção do Estado nos países industrializados e no Brasil. Tese (Concurso para Professor Titular) - Instituto de Economia Industrial, Universidade Federal do Rio de Janeiro, Rio de Janeiro, 1988.

ERBER, F. S. The Development of the 'Electronics Complex' and government policies in Brazil. World Development, v. 13, n. 1, 1985.

ERBER, F. S.; ARAUJO Jr, J. T. Notas sobre a indústria de bens de capital: tecnologia e setor público. Pesquisa e Planejamento Econômico, v. 3, n. 1, 1973.

ERBER, F.; CASSIOLATO, E. Política industrial: teoria e prática no Brazil e na OCDE. Revista de Economia Politica, v. 17, n. 2, abr./jun., 1997. 
KUPFER, D.; FERRAZ, J. C.; MARQUES, F. "The return of industrial policy in Brazil". In: STIGLITZ, J. (Org.). The industrial policy revolution I: The role of government beyond ideology. 1. ed. Londres: Palgrave, 2013, p. 327-339.

KUPFER, D. “A indústria brasileira após a abertura”. In: CASTRO, A. C. et al. (Orgs.). Brasil em desenvolvimento: economia, tecnologia e competitividade. Rio de Janeiro: Ed. Civilização Brasileira, 2015, p. 201-232.

KUPFER, D.; HAGUENAUER, L. "Dimensão estrutural da indústria Brasileira”. In: COUTINHO, L.; FERRAZ, J. C. (Orgs.). Estudo da competitividade da indústria Brasileira. Campinas: Hucitec, 1994

KUPFER, D.; FERRAZ, J. C.; PAULA, G. de. “Política industrial”. In: KUPFER, D.; HASENCLEVER, L. (Orgs.). Economia industrial: fundamentos teóricos e práticas no Brasil. 1. ed. Rio de Janeiro: Campus, 2002.

KUPFER, D.; FERRAZ, J. C.; HAGUENAUER, L. "Competição e internacionalização da indústria brasileira”. In: BAUMANN, R. (Org.). O Brasil e a economia global. Rio de Janeiro: Campus, 1995.

MENDONÇA, H. F. Três ensaios sobre a dívida pública e a determinação das taxas de juros na economia brasileira. Finanças públicas: VIII Prêmio Tesouro Nacional - 2003. Tese sobre Finanças Públicas: Coletânea de monografias. Secretaria do Tesouro Nacional. Brasília: Editora Universidade de Brasília, 2004, p. 91.

MONTEIRO FILHA, D. C., PRADO, L. C. D.; LASTRES, H. M. M. Estratégia de desenvolvimento, política industrial e inovação: ensaios em memória de Fabio Erber. Rio de Janeiro: BNDES, 2014.

MONTEIRO FILHA, D. C.; ANDRADE, J. A. P. "Pensando e implementando políticas: a contribuição de Fabio Erber no BNDES”. In: MONTEIRO FILHA, D. C., PRADO, L. C. D.; LASTRES, H. M. M. Estratégia de desenvolvimento, política industrial e inovação: ensaios em memória de Fabio Erber. Rio de Janeiro: BNDES, 2014, p. 336-338.

ORLÉAN, A. Pour une approche cognitive des conventions économique. Révue Économique, v. 40, n. 2, 1989. Disponível em: <www.persee.fr/doc/reco_0035-2764_1989_ num_40_2_409140>. Acesso em: 24 fev. 2017.

PRADO, L. C. D. "Fabio Erber: o economista e suas circunstâncias". In: MONTEIRO FILHA, D. C.; PRADO, L. C. D.; LASTRES, H. M. M. Estratégia de desenvolvimento, política industrial e inovação: ensaios em memória de Fabio Erber. Rio de Janeiro: BNDES, 2014.

ROSTOW, W. The stages of economic growth. Cambridge: Cambridge University, 1964.

SCHUMPETER, J. Economic doctrine and method: an historical sketch. London: George Allen \& Unwin, 1954 (first published 1912).

SERFATI, C. "O papel ativo dos grupos predominantemente industriais na financeirização da economia”. In: CHESNAIS, F. A mundialização financeira: gênese, custos e riscos. São Paulo: Xamã, 1998. 